\title{
CONTAMINAÇÃO MERCURIAL EM PEIXES DO RIO MADEIRA: RESULTADOS E RECOMENDAÇÕES PARA CONSUMO HUMANO.
}

\author{
Carlos R. PADOVANI' ${ }^{\text {, Bruce R. FORSBERG }}{ }^{2}$, Tania P. PIMENTEL ${ }^{2}$
}

\begin{abstract}
RESUMO - A concentração de mercúrio total foi determinada em onze espécies de peixes coletados de setembro a outubro de 1991, na área de garimpo de ouro da Cachoeira de Teotônio e da área considerada controle em Guajará-Mirim, ambas no rio Madeira, Estado de Rondônia. Utilizou-se, para a análise, a técnica de espectrofotometria de absorção atômica com gerador de vapor frio de $\mathrm{Hg}$. Quase todos os peixes predadores da área de garimpo tiveram concentraçōes de mercúrio acima do nível crítico de $0,5 \mu \mathrm{g} \cdot \mathrm{g}^{-1}$ permitido para consumo humano pelo Ministério da Saúde do Brasil e Organização Mundial de Saúde, sendo bem maiores que as concentrações de mercúrio nas espécies predadoras da área controle, evidenciando a influência do garimpo de ouro na contaminação dos peixes por mercúrio. As espécies não-predadoras tiveram concentraçōes de mercúrio abaixo daquelas das espécies predadoras para as duas áreas, indicando o efeito da biomagnificação do mercúrio na cadeia alimentar. Procurou-se estabelecer limites para o consumo de peixes pelas populações humanas da área de garimpo estudada, calculando-se a taxa de ingestão necessária para se desenvolver os primeiros sintomas de contaminação mercurial. Concluiu-se que espécies como o pacu podem ser consumidas sem restrição, já os peixes como matrinchã, curimatã, mandi e tucunaré, deveriam ser consumidos com moderação e que a maioria dos peixes predadores (em geral Siluriformes), deveriam ser consumidos apenas esporadicamente. Discutemse alguns fatores que poderiam estar interagindo no processo de contaminação por mercúrio dos ribeirinhos dessa área de garimpo.
\end{abstract}

Palavras-chaves:: mercúrio, $\mathrm{Hg}$, garimpo-de-ouro, Rio Madeira, Rondônia, amazônia, peixes.

\section{Mercury Concentrations in Fishes of the Madeira River: Results and Recomendations for Hu-} man Consumption

\begin{abstract}
Samples of eleven fish species were collected during September and October of 1991 in the gold mining area of Cachoeira de Teotônio and in the control area Guajará-Mirim, along the Madeira River, (Rondônia, Brazil) and analized for total mercury by cold vapor atomic absorption spectrofotometry. Almost all fish predators from the gold mining area had mercury concentrations above the maximal level of $0.5 \mu \mathrm{g} \cdot \mathrm{g}^{-1}$, permitted for human consumption by Brazilian Secretary of Health and the World Health Organization and much greater than those found in predatory fish species in the control area were all below this critical value $\left(0.5 \mu \mathrm{g} . \mathrm{g}^{-1}\right)$, demonstrating the influence of anthropogenic contamination in the gold mining area. In both areas, non-predators fish species had lower mercury concentrations than predators fish species, indicating the effects of biomagnification of mercury in the food chain. Safety limits for fish consumption by the human populations in this gold mining area were estabilished considering the mercury levels encontred in fish and the critical intake rate associated with the signs of mercury poisoning. Pacu, could be consumed without restrictions, matrinchã, curimatã, mandi and tucunaré, could be consumed with moderation and large predatory fish species (mostly Siluriformes), could be consumed only sporadically. Some factors that could influence mercury contaminations in "ribeirinhos" are discussed.
\end{abstract}

Key words: mercury, $\mathrm{Hg}$, gold-mining, Madeira River, Rondônia, Amazonia, físh.

EMBRAPA - CPAP (Centro de Pesquisa Agropecuária do Pantanal), Rua 21 de Setembro, 1880, Caixa Postal 109, CEP 79320.900, Corumbá, MS, Brasil.

2 Departamento de Ecologia, Instituto Nacional de Pesquisas da Amazônia, Caixa Postal 478, CEP 69011.970 Manaus, AM, Brasil. 


\section{INTRODUÇÃO}

Os garimpos de ouro da Amazônia Legal têm lançado, anualmente, mais de 100 toneladas de mercúrio no ambiente (FORSBERG, 1992). O mercúrio que entra no ecossistema aquático na forma inorgânica, pode transformar-se numa forma orgânica ao ser complexado enzimaticamente por bactérias a radicais metílicos, convertendo-se em metil-mercúrio. Nessa forma o mercúrio é rapidamente assimilado pelos organismos vivos e acumula-se nas cadeias alimentares aquáticas.

Dos organismos atingidos pela contaminação mercurial nas áreas de garimpo, os peixes destacam-se pela sua importância na alimentação humana, representando uma importante fonte de proteínas para as populações ribeirinhas (SHRIMPTON \& GIUGLIANO, 1979).

$\mathrm{O}$ uso indiscriminado de mercúrio no garimpo de ouro do rio Madeira tem resultado na contaminação do ecossistema aquático, que tem sido constatado pelas altas concentracões de mercúrio encontradas em peixes (MARTINELLI et al., 1988; MALM et al., 1990). Neste trabalho, procurou-se fazer uma nova avaliação dos níveis de mercúrio total em peixes do rio Madeira e também propor recomendações para o seu consumo pela população local.

\section{Área de estudo}

O rio Madeira, localizado à sudoeste da Amazônia Legal é o segundo maior tributário do rio Solimões/Amazonas, sua bacia hidrográfica representa $1 / 5$ da área de drenagem da Bacia Amazônica. A hidroquímica do rio Madeira caracterizase por valores neutros de $\mathrm{pH}$ e condutividades entre $80-120 \mu \mathrm{S} . \mathrm{cm}^{-1}$ (GOULDING, 1979; MALM et al., 1990).

O segmento do rio Madeira onde se localizam a área de garimpo da Cachoeira de Teotônio e a área controle de Guajará-Mirim, compreende a região das cachoeiras do alto rio Madeira (Fig. 1). Guajará-Mirim foi escolhida como área controle porque os peixes vendidos no mercado público da cidade são pescados em áreas distantes da influência do garimpo.

O nível da água do rio Madeira sobe entre os meses de setembro a março e desce no período complementar. $\mathrm{O}$ período em que foram feitas as coletas de peixe (de setembro a outubro de 1991) corresponde ao das águas mais baixas. Esta é também a época de maior produção de ouro e consequentemente de maior aporte de mercúrio para o ambiente.

\section{MATERIAIS E MÉTODOS}

$\mathrm{Na}$ área de garimpo da Cachoeira de Teotônio os peixes foram coletados diretamente dos pescadores profissionais e amadores que pescam na cachoeira com tarrafas e linhadas de mão. Na área controle de GuajaráMirim, os peixes foram coletados no mercado público, quando se sabia a procedência e data da pesca.

No campo, uma amostra de músculo foi retirada da região dorsal de cada peixe e congelada em nitrogênio líquido. As amostras foram mantidas congeladas até $o$ momento da análise. 


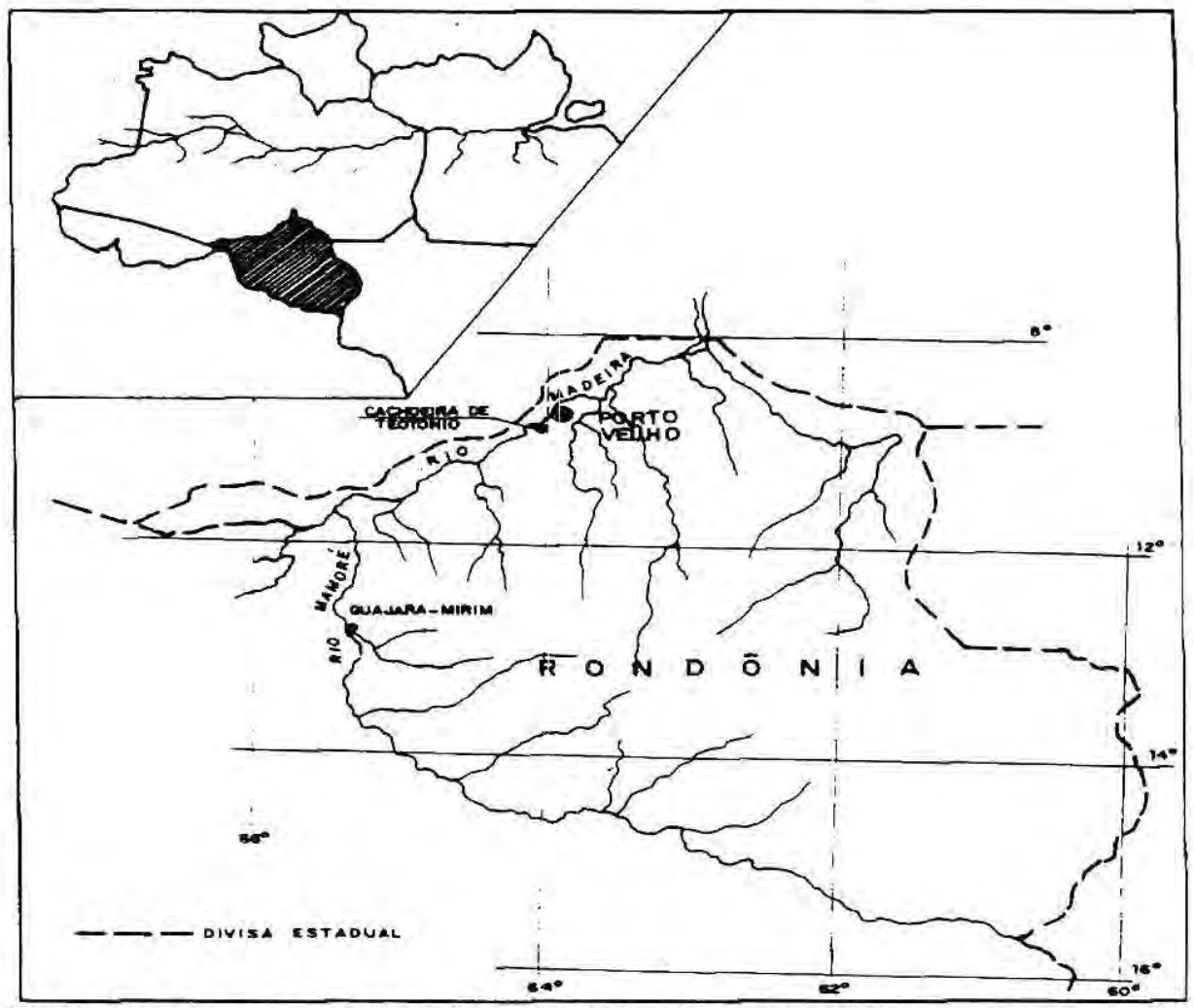

Fig. 1. Localização da área de estudo. Norte do Brasil no canto superior esquerdo e em detalhe a porção do Estado de Rondônia com a região das cachoeiras do rio Madeira. Cachoeira de Teotônio e Guajará-Mirim foram a área de garimpo de ouro e a área controle, respectivamente.

O método de análise de mercúrio utilizado foi uma modificação do método de MALM et al. (1989), com digestão, seguida pela detecção do mercúrio por um espectrofotômetro de absorção atômica, acoplado com gerador de vapor frio de $\mathrm{Hg}$.

\section{RESULTADOS E DISCUSSÃO}

\section{Concentração de mercúrio total nos peixes}

As concentrações de mercúrio total nos peixes da área de garimpo da Cachoeira de Teotônio variaram entre 0,02 a $1,15 \mu \mathrm{g} \cdot \mathrm{g}^{-1}$ (Tab. 1). As espécies predadoras Calophysus macropterus (pintadinho), Rhaphiodon vulpinus (peixe-cachorro), Pseudoplatystoma sp. (surubim), Pinirampus pirinampu (barbado) e Sorubim lima (bico-depato), tiveram concentrações médias de mercúrio total maiores que as espécies não predadoras Prochilodus nigricans (curimatã) e Mylossoma duriventre (pacu). As espécies generalistas Pimelodus blochii (mandi) e Brycon sp. (matrinchã), apresentaram concentrações médias de mercúrio total iguais aos dos peixes não-predadores (ex. matrinchã) ou intermediária entre esses dois 
Tabela 1. Concentrações médias de mercúnio total em peixes da área de garimpo da Cachoeira de Teotônio, RO. $\mathrm{N}=$ número de amostras, $\mathrm{DP}=$ desvio padrāo, (mín. máx. $)=$ valores mínimos e máximos e $\mathrm{Hg}$ $(\mathrm{ppm})=$ concentração média de mercúrio em $\mu \mathrm{g} \mathrm{g}^{-1}$ de peso fresco.

\begin{tabular}{|c|c|c|c|c|}
\hline Espécie & Alimentação & $\mathrm{N}$ & DP & $\mathrm{Hg}$ \\
\hline PREDADORES & & & (min. - máx.) & (ppm) \\
\hline $\begin{array}{l}\text { Calophysus macropterus } \\
\text { (bagre) }\end{array}$ & peixes & 1 & - & 0,90 \\
\hline $\begin{array}{l}\text { Rhaphiodon vulpinus } \\
\text { (peixe-cachorro) }\end{array}$ & peixes & 1 & - & 0,79 \\
\hline $\begin{array}{l}\text { Pseudoplatystoma sp. } \\
\text { (surubim) }\end{array}$ & peixes & 2 & $(0,70-1,03)$ & 0,86 \\
\hline $\begin{array}{l}\text { Pinirampus pirinampu } \\
\text { (barbado) }\end{array}$ & peixes & 12 & $\begin{array}{c}0,25 \\
(0,37-1,15)\end{array}$ & 0,62 \\
\hline $\begin{array}{l}\text { Sorubim Lima } \\
\text { (bico-de-sapo) } \\
\text { GENERALISTAS }\end{array}$ & peixes & 3 & $\begin{array}{c}0,22 \\
(0,32-0,74)\end{array}$ & 0,50 \\
\hline $\begin{array}{l}\text { Pimelodus blochii } \\
\text { (mandi) }\end{array}$ & $\begin{array}{l}\text { omnivoro } \\
\text { (peixes, frutos e insetos) }\end{array}$ & 10 & $\begin{array}{c}0,13 \\
(0,09-0,48)\end{array}$ & 0,26 \\
\hline $\begin{array}{l}\text { Brycon } s p . \\
\text { (matrinchã) } \\
\text { NÃO-PREDADORES }\end{array}$ & $\begin{array}{l}\text { omnívoro } \\
\text { (peixes, frutos e insetos) }\end{array}$ & 3 & $\begin{array}{c}0,04 \\
(0,08-0,17)\end{array}$ & 0,12 \\
\hline $\begin{array}{l}\text { Prochilodus nigricans } \\
\text { (curimatã) }\end{array}$ & $\begin{array}{c}\text { principalmente detritos } \\
\text { vegetais }\end{array}$ & 17 & $\begin{array}{c}0,10 \\
(0,04-0,46)\end{array}$ & 0,12 \\
\hline $\begin{array}{l}\text { Mylossoma duriventre } \\
\text { (pacú) }\end{array}$ & $\begin{array}{l}\text { predomina frutos e } \\
\text { sementes }\end{array}$ & 8 & $\begin{array}{c}0,01 \\
(0,02-0,06)\end{array}$ & 0,04 \\
\hline
\end{tabular}

Tabela 2. Concentrações médias de mercúrio total em peixes da área controle de Guajará-Mirim, RO. N = número de amostras, $\mathrm{DP}=$ desvio padrão, (mín. - máx. $)$ = valores mínimos e máximos e $\mathrm{Hg}(\mathrm{ppm})$ = concentração média de mercúrio em $\mu \mathrm{g} \mathrm{g}^{-1}$ de peso fresco.

\begin{tabular}{|c|c|c|c|c|}
\hline Espécie & Alimentação & $\mathrm{N}$ & DP & $\mathrm{Hg}$ \\
\hline & & & (mín. - máx.) & (ppm) \\
\hline PREDADORES & & & & \\
\hline $\begin{array}{l}\text { Cichla temensis } \\
\text { (tucunaré) }\end{array}$ & peixes & 5 & $\begin{array}{c}0,09 \\
(0,16-0,37)\end{array}$ & 0,28 \\
\hline $\begin{array}{l}\text { Hoplias aff. malabaricus } \\
\text { (traíra) }\end{array}$ & peixes & 19 & $\begin{array}{c}0,04 \\
(0,12-0,30)\end{array}$ & 0,20 \\
\hline $\begin{array}{l}\text { Pseudoplatystoma sp. } \\
\text { (pintado) } \\
\text { NÃO-PREDADOR }\end{array}$ & peixes & 11 & $\begin{array}{c}0,05 \\
0.09-0,25)\end{array}$ & 0,18 \\
\hline $\begin{array}{l}\text { Prochilodus nigricans } \\
\text { (curimatã) }\end{array}$ & $\begin{array}{c}\text { principalmente detritos } \\
\text { vegetais }\end{array}$ & 4 & $\begin{array}{c}0,03 \\
(0,08-0,16)\end{array}$ & 0,11 \\
\hline
\end{tabular}

grupos(ex. mandi). Foram consideradas aqui como espécies predadoras aquelas que se alimentam basicamente de peixes e as não-predadoras aquelas que consomem principalmente material vegetal. $\mathrm{O}$ termo "generalista" foi usado para designar peixes como o mandi e matrinchã, com hábito alimentar omnívoro. A determinação das 
três categorias de hábito alimentar foi elaborada consultando-se GOULDING (1979).

$\mathrm{Na}$ área controle de GuajaráMirim as concentrações de mercúrio total nos peixes variaram de 0,08 a $0,37 \mu \mathrm{g} \cdot \mathrm{g}^{-1}$. As espécies predadoras Cichla temensis (tucunaré), Hoplias aff malabaricus (traíra) e Pseudoplatystoma sp. (surubim), tiveram concentrações de mercúrio total bem abaixo daquelas encontradas para as espécies predadoras da área de garimpo (Tabs. 1 e 2). As maiores concentrações de mercúrio total na área de garimpo aparentemente mostram a influência da contaminação mercurial associada com o garimpo.

A maior concentração encontrada em peixes predadores reflete a biomagnificação do mercúrio nas cadeias alimentares. Assim, os predadores no final da cadeia tendem a ter concentrações maiores que os não-predadores (e.g. herbívoros), que se situam no início das cadeias alimentares. Parte da biomagnificação parece ocorrer porque em geral os predadores são maiores e têm um tempo de vida mais longo, acumulando mais mercúrio em seus corpos que suas presas (WILLIAMS \& WEISS, 1973).

As concentracões médias de mercúrio das espécies predadoras da área de garimpo foram igual (surubim) ou acima do nível máximo de $0.5 \mu \mathrm{g} \cdot \mathrm{g}^{-1}$ permitido pelo Ministério da Saúde do Brasil (BRASIL, 1975) e Organização Mundial de Saúde (WHO, 1976) para consumo humano, enquanto que as espécies não-predadoras e as generalistas, tiveram valores bem abaixo deste nível. $\mathrm{Na}$ área controle, todas as espécies coletadas tiveram concentrações de mercúrio total bem abaixo do nível crítico.

Estudos anteriores de contaminação mercurial no garimpo do rio Madeira (MARTINELLI et al., 1988; MALM et al., 1989) e em áreas de garimpo de Carajás, PA. (COMPANHIA VALE DO RIO DOCE, sem data) também mostraram concentrações de mercúrio total acima do nível crítico permitido pelo MSB e WHO, para peixes predadores. Os dados deste estudo, mostram que o problema da contaminação mercurial em peixes da área de garimpo do rio Madeira continua.

\section{Recomendações para consumo humano}

Embora tenha se encontrado em áreas de garimpo peixes com concentrações de mercúrio acima dos níveis críticos permitidos pela legislação brasileira (BRASIL, 1975), pouco tem sido feito para orientar os ribeirinhos destas áreas, que dependem do peixe como fonte de proteína. A ingestão de peixe contaminado pelos ribeirinhos, ocorre devido à ignorância da existência da contaminação e dos riscos da toxidez do mercúrio ou por falta de opção e/ou condições de obter outra fonte de proteína.

Um programa educativo com mensagens simples e compreensíveis deveria ser formulado e aplicado em todas as áreas de garimpo para orientar os ribeirinhos sobre os perigos do mercúrio. A recomendação mais simples seria de evitar ou reduzir ao mínimo o consumo de peixes predadores como o bagre, peixecachorro, pintado, barbado, surubim, dourado e dourada. Já as espécies de peixes 
três categorias de hábito alimentar foi elaborada consultando-se GOULDING (1979).

$\mathrm{Na}$ área controle de GuajaráMirim as concentrações de mercúrio total nos peixes variaram de 0,08 a $0,37 \mu \mathrm{g} \cdot \mathrm{g}^{-1}$. As espécies predadoras Cichla temensis (tucunaré), Hoplias aff malabaricus (traíra) e Pseudoplatystoma sp. (surubim), tiveram concentrações de mercúrio total bem abaixo daquelas encontradas para as espécies predadoras da área de garimpo (Tabs. 1 e 2). As maiores concentrações de mercúrio total na área de garimpo aparentemente mostram a influência da contaminação mercurial associada com o garimpo.

A maior concentração encontrada em peixes predadores reflete a biomagnificação do mercúrio nas cadeias alimentares. Assim, os predadores no final da cadeia tendem a ter concentrações maiores que os não-predadores (e.g. herbívoros), que se situam no início das cadeias alimentares. Parte da biomagnificação parece ocorrer porque em geral os predadores são maiores e têm um tempo de vida mais longo, acumulando mais mercúrio em seus corpos que suas presas (WILLIAMS \& WEISS, 1973).

As concentracões médias de mercúrio das espécies predadoras da área de garimpo foram igual (surubim) ou acima do nível máximo de $0.5 \mu \mathrm{g} \cdot \mathrm{g}^{-1}$ permitido pelo Ministério da Saúde do Brasil (BRASIL, 1975) e Organização Mundial de Saúde (WHO, 1976) para consumo humano, enquanto que as espécies não-predadoras e as generalistas, tiveram valores bem abaixo deste nível. Na área controle, todas as espécies coletadas tiveram concentrações de mercúrio total bem abaixo do nível crítico.

Estudos anteriores de contaminação mercurial no garimpo do rio Madeira (MARTINELLI et al., 1988; MALM et al., 1989) e em áreas de garimpo de Carajás, PA. (COMPANHIA VALE DO RIODOCE, sem data) também mostraram concentrações de mercúrio total acima do nível crítico permitido pelo MSB e WHO, para peixes predadores. Os dados deste estudo, mostram que o problema da contaminação mercurial em peixes da área de garimpo do rio Madeira continua.

\section{Recomendações para consumo humano}

Embora tenha se encontrado em áreas de garimpo peixes com concentrações de mercúrio acima dos níveis críticos permitidos pela legislação brasileira (BRASIL, 1975), pouco tem sido feito para orientar os ribeirinhos destas áreas, que dependem do peixe como fonte de proteína. A ingestão de peixe contaminado pelos ribeirinhos, ocorre devido à ignorância da existência da contaminação e dos riscos da toxidez do mercúrio ou por falta de opção e/ou condições de obter outra fonte de proteína.

Um programa educativo com mensagens simples e compreensíveis deveria ser formulado e aplicado em todas as áreas de garimpo para orientar os ribeirinhos sobre os perigos do mercúrio. A recomendação mais simples seria de evitar ou reduzir ao mínimo o consumo de peixes predadores como o bagre, peixecachorro, pintado, barbado, surubim, dourado e dourada. Já as espécies de peixes 
como o pacu, matrinchã e curimatã, poderiam ser mais consumidos.

Além da falta de orientação, não tem havido uma preocupação em se estabelecer limites quantitativos para o consumo de peixe contaminado. Embora a determinação desses limites exija uma análise mais criteriosa, esta se baseia na regra simples de que quanto mais contaminado for o peixe, menos ele deve ser consumido.

O metil-mercúrio tem uma meia vida de 70 dias no organismo humano (WHO, 1976), o que significa que o organismo se auto depura do mercúrio ingerido. Fazendo-se uma analogia do organismo humano com um sistema simples onde há uma entrada, um reservatório e uma saída, as concentrações de mercúrio no organismo vão depender do balanço entre a entrada e a saída desse metal pesado (Fig. 2). A ingestão contínua a concentração de mercúrio no organismo vai depender da concentração no peixe e da taxa de ingestão. A taxa de ingestão pode ser medida em termos de número de refeições por semana ou em gramas de peixe ingerido por dia. Para o número de refeições por semana, usa-se como base de cálculo um valor médio de 200 gramas de peixe por refeição.

Essas duas formas de medir a taxa de ingestão são extremamente úteis quando se pensa em termos de quanto mercúrio está sendo ingerido. A taxa de ingestão de mercúrio que causa os primeiros sintomas de contaminação mercurial (a perda de sensibilidade nas extremidades do corpo) em pessoas adultas mais sensíveis é de 4 microgramas de mercúrio por quilograma de peso corporal por dia (4 $\left.\mu \mathrm{g} \mathrm{Hg} \cdot \mathrm{kg}^{-1} \cdot \mathrm{d}^{-1}\right)$ (STATE OF CALIFORNIA, 1987).

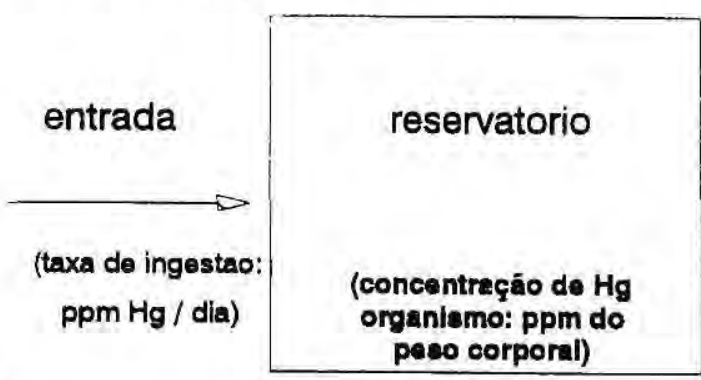

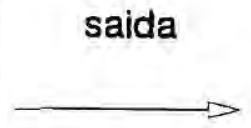

(taxa de excrecao:

ppm Hg / dia)

Fig. 2. Modelo do organismo humano como um sistema simples onde há três elementos principais: uma entrada, o reservatório e uma saída. Às taxas de ingestão e excreção descrevem os fluxos e a concentração de $\mathrm{Hg}$ no organismo descreve o acúmulo de $\mathrm{Hg}$ no sistema.

de peixe contaminado em taxas maiores que a capacidade do organismo em excretar o mercúrio, pode causar seu acúmulo no organismo, provocando efeitos nocivos.

Considerando apenas a entrada de mercúrio e mantendo a saída fixa,
Recomenda-se que a dose máxima aceitável (DMA) seja dez vezes menor que esse valor, por medida de segurança, sendo aceito então um valor de $0,4 \mu \mathrm{g} \mathrm{Hg} \cdot \mathrm{kg}^{-1} \cdot \mathrm{d}^{-1}$.

Para uma pessoa adulta de $60 \mathrm{~kg}$ de peso corporal a DMA crítica será 
de $24 \mu \mathrm{g} \mathrm{Hg} . \mathrm{d}^{-1}$. A partir desse valor, pode-se calcular o quanto de peixe que uma pessoa adulta de $60 \mathrm{~kg}$ deveria ingerir para ter uma taxa de ingestão de $24 \mu \mathrm{g} \mathrm{Hg} . \mathrm{d}^{-1}$, e esse, seria o consumo máximo aceitável de peixe (CMA).

Considerando o valor mínimo $\left(0,04 \mu \mathrm{g} \cdot \mathrm{g}^{-1}\right)$ e máximo $\left(2,7 \mu \mathrm{g} \cdot \mathrm{g}^{-1}\right) \mathrm{da}$ concentração de mercúrio encontrada em peixes da área de garimpo da Cachoeira de Teotônio, desse estudo e dos dados de MALM et al. (1990), calculou-se para um intervalo de 0,01 a $3 \mu \mathrm{g} . \mathrm{g}^{-1}$ limites máximos de consumo em termos de gramas de peixe por refeição por dia e número de refeições com 200 gramas de peixe por semana, obtendo-se a curva da Figura 3. Os cálculos foram feitos da seguinte maneira:

CMAD (consumo máximo admissível diário):

$\frac{24 \mu \mathrm{g} \mathrm{Hg} \text { pessoa }}{\mu \mathrm{g} \text { Hg.grama de } \text { dia }^{-1}}=$ gramas de $^{-1}$ peixe pessoa ${ }^{-1} \cdot$ dia $^{-1}$

CMAS (consumo máximo admissível semanal):

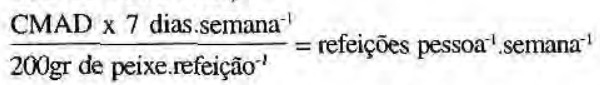

A curva da Figura 3 mostra que para espécies com concentrações de mercúrio total baixas não seria necessário limitar seu consumo. No caso do pacu, seria necessário a ingestão de 600 gramas diária ou 25 refeições por semana para se alcançar o nível crítico de $24 \mu \mathrm{g} \mathrm{Hg}$, uma taxa de ingestão muito acima do consumo normal de peixe na região. Espécies como matrinchã, curimatã, mandí e tucunaré, já deveriam ser ingeridas com moderação, pois o nível crítico de $24 \mu \mathrm{g} \mathrm{Hg}$ poderia ser alcançado com uma refeição diária de 200 gramas de peixe. Espécies que apresentaram níveis de mercúrio total acima de 0,5 $\mu \mathrm{g} . \mathrm{g}^{-1}$ deveriam ser consumidas apenas esporadicamente, pois uma única refeição já excede o limite crítico. É importante lembrar que os valores de concentração de mercúrio total dos peixes apresentados aqui são valores médios de alguns indivíduos e representam a época em que os peixes foram coletados. Variações nas concentrações de mercúrio nos peixes podem ocorrer em diferentes épocas e intensidades de atividade garimpeira, podendo alterar a quantidade de peixe que pode ser consumida.

Embora os peixes sejam uma importante fonte de proteína para os ribeirinhos, não se conhece as taxas de consumo em gramas de peixe por dia ou número de refeições por semana, dessas populações. É esperado que o consumo das diferentes espécies de peixes variem ao longo do ano de acordo com a variação na sua abundância, facílidade de captura, tamanho dos peixes e preferência dos ribeirinhos. Seria importante conhecer a variação desses parâmetros, para se avaliar com segurança os efeitos da contaminação por mercúrio.

Na Cachoeira de Teotônio a pesca é fortemente sazonal (GOULDING, 1979), devido às migrações anuais dos peixes. $\mathrm{Na}$ época de subida destes (piracema), diferentes espécies predadoras e nãopredadoras podem ser pescadas no mesmo local, diversificando o consumo de peixes com diferentes concentrações de mercúrio.

Os fatores citados acima podem minimizar a contaminação das populações humanas por mercúrio ingerido via peixe. Porém, é importante 


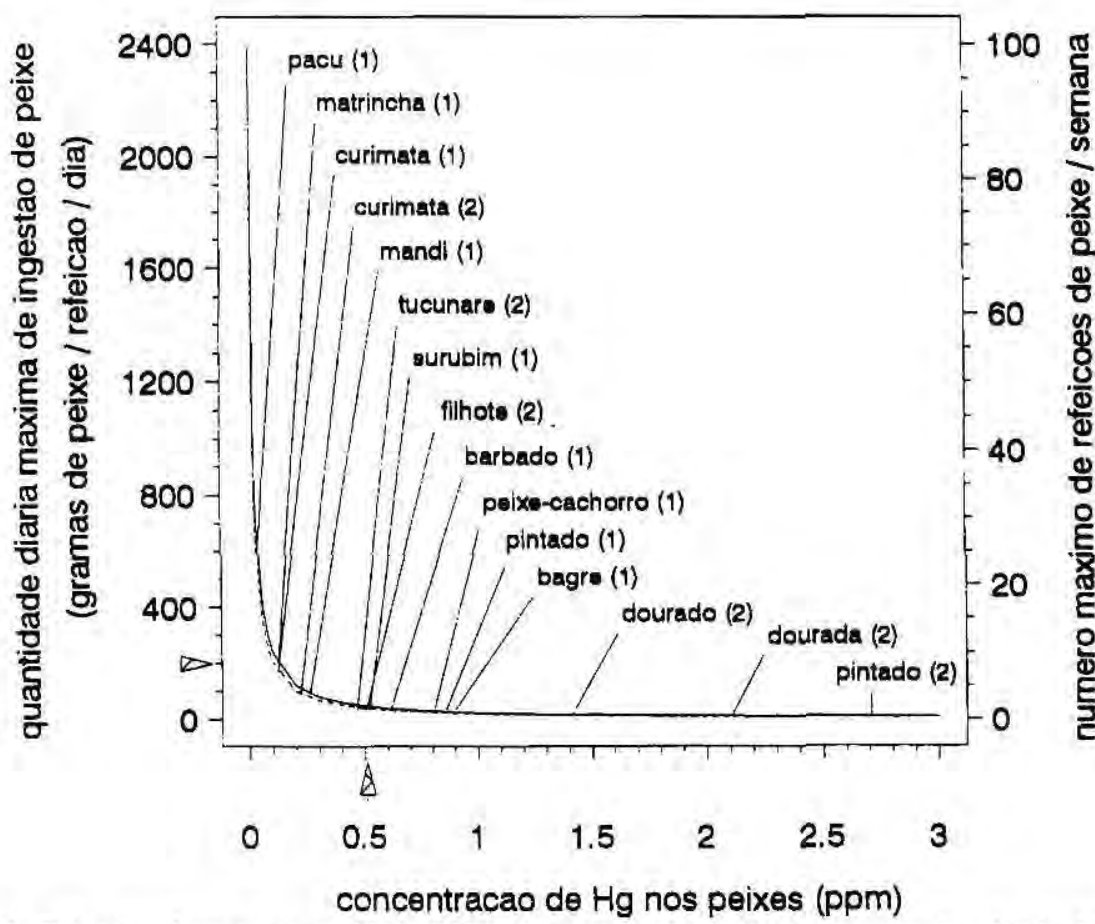

Fig. 3. Curva que descreve a quantidade diária máxima de ingestão de peixe (gramas de peixe / refeição / dia) e número máximo de refeições de peixe (200 gramas) / semana, em função da concentração de mercúrio nos peixes, para uma pessoa adulta de $60 \mathrm{~kg}$. A posição de cada espécie de peixe ao longo da curva está indicada. (1) dados desse trabalho (2) dados de MALM et al., 1990. $\triangleright$ peso médio de peixe por refeição (200 gramas) $\triangle$ nível crítico permitido pela Secretaria da Saúde para consumo humano.

lembrar que a análise da CMA feita aqui é extremamente conservadora e que em condições agudas os riscos de contaminação com consequências mais sérias não devem ser descartados.

\section{CONCLUSÕES}

Os resultados apesentados aqui para a área de garimpo da Cachoeira de Teotônio, mostram que os peixes predadores estão contaminados com mercúrio em níveis preocupantes, inviabilizando seu consumo rotineiro.

Devido ao fato do peixe ser a principal fonte de proteínas para as populações ribeirinhas, a proibição do seu consumo não seria uma medida eficiente. Um programa educacional feito com uma linguagem acessível, deveria ser colocado em prática para esta e outras áreas de garimpo, com o objetivo de minimizar a contaminação humana por mercúrio via peixe.

Estudos ecotoxicológicos e epidemiológicos detalhados seriam necessários para que o problema de contaminação mercurial das áreas de garimpo progrida para um conhecimento científico e não fique apenas a nível de manchetes de jornais.

\section{AGRADECIMENTOS}

Agradecemos ao Secretário da SEDAM, RO, Sr. Francisco Pereira e 
à Silvia Metchko pelo apoio entre as instituições SEDAM / INPA e ao Sr. Engo Maroto e Sr. Gama pelo apoio no trabalho de campo e em Porto Velho. Ao M.Sc. Jorge Porto pela cooperação no trabalho de campo e ajuda na identificação dos peixes. Ao $\mathrm{CNPq}$ através do projeto RHAE pela conceção da bolsa de estudos à Carlos R. Padovani. Este projeto foi financiado pela Fundação Banco do Brasil e pela NSF (grant DEB-8107522). Contribuição número 000 do projeto CAMREX. Agradecemos também ao Dr. Olaf Malm do Instituto de Biofisica Carlos Chagas Filho da UFRJ pelas críticas e sugestões feitas ao manuscrito.

\section{Bibliografia citada}

BRASIL. 1975. Ministério da Saúde. Resolução no 18175 da Comissão Nacional de Normas e Padrões Para Alimentos. Diário Oficial da União, 9 de dezembro de 1975.

COMPANHIA VALE DO RIO DOCE. (sem data). Monitoramento do Mercúrio na Área do Projeto Carajás da Companhia Vale do rio Doce (CVRD), Estado do Pará, Brasil. Relatório Técnico. 26 p.

FORSBERG, B. R. 1992. Mercury Contamination in the Amazon: Another Minamata? Wather Report 2(4): 6-7.

GOULDING, M. 1979. Ecologia da Pesca do rio Madeira. Conselho Nacional de Desenvolvimento Científico e Tecnológico. Instituto Nacional de Pesquisas da Amazônia. Editora Falangola. Belém. Pará.
MALM, O.; PFEIFFER, W. C.; BASTOS, W. R.; SOUZA, C. M. M. 1989. Utilização do acessório de geração de vapor frio para análise de mercúrio em investigações ambientais por espectrofotometria de absorção atômica. Ciência e Cultura, 41: 88-92.

MALM, O,; PFEIFFER, W. C.; SOUZA, C. M.; M. REUTHER, R. 1990. Mercury polution due to gold mining in the Madeira River Basin, Brasil. Ambio, 19; 11-15.

MARTINELLI, L. A.; FERREIRA, J. R.; FORSBERG, B. R.; VICTÓRIA, R. L. 1988. Mercury contamination in the Amazon: A gold rush consequence. Ambio, 17: 252-254.

SHRIMPTON, R.; GIUGLIANO, R. 1979. Consumo de alimentos e alguns nutrientes em Manaus, Amazonas. 197374. Acta Amazonica, 9: 117-141.

STATE OF CALIFÓRNIA. 1987. Department of Health Services. Methylmercury in Northern Coastal Mountain Lakes: Guidelines for Sport Fish Consumption for Clear Lake (Lake County), Lake Berryessa (Napa County), and Lake Herman (Solano County). Technical Report. 29 p.

WHO 1976. Environmental Health Criteria. I. Mercury. World Health Org., Geneva 1-131.

WILLIAMS, P. M.; WEISS, H. V. 1973. Mercury in the marine environment: Concentration in sea water and in pelagic food chain. J. Fish. Res, Bd. Can. 30: 293-295. In: WATRAS, C. J. 1992. Mercury and Methilmercury in individual zooplancton: Implications for bioaccumulation. Limnol. Oceanogr., 37(6): 1313-1318. 